\title{
Research on Risk Control Strategies of Consumer Finance Based on Big Data Technology
}

Ziwei Wang*

Shanghai Lixin University of Accounting and Finance, Shanghai 200000, China. E-mail: wangziweiapp@126.com

\begin{abstract}
China's economic development is from high speed to high quality. Developing consumer finance has become a new growth point of China's economic development and one of the important ways to expand domestic demand. Consumer finance is based on the development of new generation Internet technology and big data, becoming a new trend of China's financial development and attracting the attention of various industries.
\end{abstract}

Keywords: Big Data Technology; Consumer Finance; Risk Control Strategy; Research

\section{Introduction}

To develop the consumer finance based on big data technology, it is necessary to strengthen the formulation and perfection of relevant laws and regulations, build a supervision system and enhance the risk management of consumer finance based on big data technology.

\section{Risks of consumer finance based on big data technology}

\subsection{The scope of financial supervision needs to be expanded urgently}

Financial big data technology has upgraded the service and promoted innovation of financial products in some extent, and also aggravated the competition of financial industry. In terms of financial risks, what is closely related is technology ${ }^{[1]}$. Besides traditional risks, the increase of technical risks also increases the risks of financial supervision. Therefore, financial technology must be integrated into financial supervision in China. In this context, the construction of big data is far from ideal ${ }^{[2]}$. In the context of financial big data development, the application of technology has become indispensable, which is not for competition, but for the development of financial institutions ${ }^{[3]}$. It once took a long time for the risk management of financial institutions, as tests and experiments were needed after the completion of the research and development. However, the increasing competitive pressure of financial big data has shortened the time of products research and development to application into a few months, which increases the financial risks. As for the sales of financial products, the promotion channels are expanding, and businesses need to be combined with computers, which poses a challenge to the design and structure of computers and their scalability. With the support of big data, the risk management ability of the financial industry has improved, with more complex and safer operation. Moreover, the connection between financial institutions and the outside has become closer through cooperation, alliance and technology outsourcing. Due to the increased externality, it is very difficult to control the management of the third party. In addition, the Internet has developed rapidly in recent years ${ }^{[4]}$. The Internet, as a global open network, has provided con- 
venience for manufacturers and customers all over the world. However, because of the instability of its information router, the risks have increased, both to the safety of customers and their information. Therefore, the protection of customers' privacy in the Internet environment has become an important thing. Under the new risk management mode, the risk management of financial institutions must be adjusted so as to manage and control the risks. Driven by interests, the financial industry applying big data may bring itself greater risks that are higher than traditional financial risks ${ }^{[5]}$. Once the loss is caused, it will be huge, and the damage will worse than that of the traditional regulatory risks. As far as financial supervision is concerned, one of its main tasks is to ensure that financial institutions have certain risk management on related technologies, and these technologies must play the role to control the overall financial risks within a proper range. The development, application and risk management of big data technology have a certain impact on the overall business objectives of financial institutions, requiring the supervision bureau of financial institutions to attach great importance to reduce risks ${ }^{[6]}$.

\subsection{Unreasonable organizational structure of consumer financial risk management}

Banks are responsible for the evaluation of consumer finance business, and there is no specific risk management department to control the risks of consumer finance business. The review department will review the consumer finance policy reports of banks by reading the paper materials and asking the consumer finance personnel to check the relevant qualifications, so as to determine whether the business should be submitted to the Consumer Finance Review Committee for review. In the whole process, the evaluation department, as the key back-end decision-making department of consumer finance business, does not play the role of preventing and controlling consumer finance risks. Receiving the report from the review department, the general manager makes a decision according to the comprehensive opinions of the review department. There is no special risk management department to take the lead in implementing consumer financial risk management in the whole consumer financial business process ${ }^{[7]}$.

\subsection{The comprehensive quality of consumer financial risk management personnel needs to be improved}

Outstanding business skills and professional ethics are prerequisites for excellent consumer finance personnel. The increased competitiveness of consumer finance market and the detection and prevention of consumer finance risks are inseparable from the solid business ability of personnel. Eliminating and preventing employees from illegal behaviors is related to good professional ethics of employees ${ }^{[8]}$. Employees often encounter consumer financial risks led by violation of professional ethics and illegal business practices. In addition, consumer financial risks may be caused by the ideological and moral problems of employees.

\subsection{More attention to explicit risk management than implicit risk management}

Explicit risks refer to the explicit risks which is easy to be found and affects enterprises to some extent in the short time. Implicit risks refer to risks of short-term difficulties in discovery or valuation, having a far-reaching impact on the long-term stable operation of enterprises. Although Chinese enterprises have raised their awareness of risk management in recent years, they are unable to get rid of the extensive business model and lack of research and prevention of hidden risks. In addition, the institutional environment and legal rules for the survival of enterprises are still not perfect. The defects and deficiencies in consumer finance laws and regulations, and an effective consumer finance legal system to be formed, with the lag and imperfection of corporate culture construction, are hidden dangers for the stable operation and development of enterprises.

\section{Risk control strategies of consumer finance based on big data technology}

\subsection{To speed up the construction of regulatory information system}

China's current laws and regulations on consumer finance supervision are not perfect, and lag behind in some perspectives. Perfecting laws and regulations can provide effective legal basis for the development and operation of con- 
sumer finance industry. The uncertain factors in the operation of consumer finance led to the loss of basis for the supervision of consumer finance, causing low efficiency of supervision. In this context, China must strengthen the construction of the legal system of consumer finance, using legal means to protect the operation and promote the development of consumer finance, and improving the level and efficiency of legal supervision. Moreover, the construction of the current consumer finance system should consider the development of consumer finance big data, improve its operability and solve the complexity brought by risks, thus highlighting the importance of consumer finance supervision ${ }^{[9]}$. The effective implementation and guarantee system of consumer finance supervision are also important, which requires a matched supporting system of laws and regulations and a system for monitoring information. The application of big data technology also makes monitoring complicated, resulting in the failure of traditional supervision means. However, big data technology can become a powerful tool for supervision. After adopting big data technology for supervision, the supervisory department has promoted the daily supervision work, combined on-site inspection with off-site inspection, realizing the modernization of supervision means. In some western countries, the consumer financial supervision has also been reformed. Computer supervision means including computers and systems are adopted, and some models are established, the main purpose of which is to provide powerful help for risk prediction. China draws lessons from some developed countries' experiences in consumer financial supervision methods, including management level and market risk analysis. The accuracy and science of data is important, and should focus on the analysis and testing of models. The construction of China's regulatory information system learnt from foreign countries, and absorbed the essence and proper parts of the regulatory systems into China's system to form a set of consumer financial regulatory system. By establishing such a system, the big data work of consumer finance in China can be reformed and promoted, and the accuracy and scientificity of the supervision mechanism of consumer finance in China can also be increased.

\subsection{To perfect the risk management organization of consumer finance}

The main purpose of establishing a sound risk management organization is to improve the risk control level and enhance the risk management ability of consumer finance business. To implement the scientific concept of development, it is necessary to standardize the rational competition in the consumer financial market. Development does not mean rapid development, but effective and sustainable development based on certain situation. This requires to work out a standardized and reasonable sustainable scientific development concept. A stable market order is important to the consumer financial market. To create a good market order, everyone should take his work seriously in any link and maintain this order together. Only in this way, we can standardize the development of consumer financial market. In addition, the Consumer Financial Risk Management Committee and two other Consumer Financial Risk Review Committees were established, and improved the overall professional level of the committees. At the same time, we should focus on national policies, new business and new products. Moreover, the management should lead by example, never interfering with the normal work of the committees, so as to effectively prevent and control financial risks.

\subsection{To improve the overall quality of consumer finance personnel}

Improving the overall quality of consumer finance personnel, includes improving the professional quality and moral ethics of consumer finance personnel. On the one hand, banks should establish and perfect a scientific training system according to their work characteristics, enhance the work training for employees, including social quette, business training, and management training. On the other hand, moral cultivation should be carried out, such as publicizing employees' exemplary deeds. It is necessary to combine business summary and ideological summary into the regular work report, and include employees' ideological assessment into the year-end assessment index, to stimulate personal ideological and moral education, and finally reduce the consumer financial risks brought by ethical issues of employees. Furthermore, severe punishment should be given to those who violate the rules of the consumer financial market, in order to put an end to the behavior of taking kickbacks and bidding up prices ${ }^{[10]}$. At the same time, it is necessary to control the composition of the review body and cultivate a team with clear attitude and serious responsibility. Besides, teamwork is also important. The review body must have a deep and clear understanding of supervision, and 
provide a fair and just environment for competition in the consumer financial market.

\subsection{To perfect the risk management process of consumer finance}

In the process of risk management, it is necessary to find out and solve problems from inside and optimize the risk management procedures of banks. The operational risk control of consumer finance business is mainly the risk control of business processes. Therefore, consumer financial institutions should be selected carefully as the cooperator. They should be with strong consumer financial ability and timely compensation ability.

\section{Conclusion}

Consumer finance based on big data technology, which is an unprecedented integration of traditional consumer credit and Internet innovative business model, and its risks cover the common risks of the former and the special risks of the latter. Only by strengthening the supervision of the network, and improving the level of risk management and prevention technologies, we can promote the development of consumer finance.

\section{References}

1. Li X. Research on risk control strategies of consumer finance based on big data technology (in Chinese). Modern Economic Information 2020; (14): 124 - 125.

2. Gao Y. Research on the development strategies of Internet consumer finance in the new era (in Chinese). Market Modernization 2020; (9): 130 - 131.

3. Du F, Zhang X, Xiao Y, et al. Innovation on financial business based on big data - Taking blue-collar consumer finance as an example (in Chinese). Market Modernization 2020(04): $102-103$.

4. Xia D. Big data driven mode based on Internet finance (in Chinese). Electronic Technology \& Software Engineering 2019; (24): $144-145$.

5. Wang T. On the risk control logic of Internet consumer finance (in Chinese). Modern Economic Information 2019; (21): $275-276$.

6. Xie F. The development of consumer finance innovation under the background of Internet and risk control studies (in Chinese). The Journal of Shandong Agriculture and Engineering University 2019; 36(7): 78 - 83.

7. Xie X. On Internet consumer finance driven by big data technology (in Chinese). Marketing Management Review 2019; (7): $34-35$.

8. Jiang Y. Research on the promotion path of consumer finance business of commercial banks under the background of "Internet plus" (in Chinese). Journal of Financial Development Research 2018; (9): 86 - 88.

9. Ji Y, Shen Y. Big data technology promoting better ecology of consumer finance (in Chinese). Tsinghua Financial Review 2018; (1): 40 - 41.

10. Zhao D. Research on Internet consumer finance driven by big data technology (in Chinese). Journal of Finance and Economics 2017; (1): 41 - 45, 92. 